\title{
Sustainability indicators for industrial ovens and assessment using Fuzzy set theory and Monte Carlo simulation
}

\author{
F. Pask ${ }^{* 1,2}$, P. Lake ${ }^{1}$, A. Yang ${ }^{3}$, H. Tokos ${ }^{4}$, J. Sadhukhan ${ }^{2}$ \\ 1 3M Centre, Cain Road, Bracknell, Berkshire RG12 8HT, UK \\ ${ }^{2}$ Centre for Environmental Strategy, University of Surrey, Guildford, GU2 7XH, UK. \\ ${ }^{3}$ Department of Engineering Science, University of Oxford, Oxford, OX1 3PJ, UK \\ ${ }^{4}$ Department of Chemical and Process Engineering, University of Surrey, Guildford, GU2 7XH, UK. \\ *Corresponding author; Tel: +00447952981027, fpask@mmm.com, freddie.pask@gmail.com
}

\section{Abstract}

Industrial ovens play a significant role in many manufacturing and process industries. Despite the desire to enhance sustainability throughout this sector, research looking to improve the sustainability of industrial ovens is in its infancy. This paper presents seven sustainability indicators to assess potential oven investment; these include system air flow, production efficiency, operating costs, quality, capital investment, toxicity and employment opportunity. The indicators are straightforward, can be scored with readily available data and have been weighted by industrial experts. A hybrid multi-criteria approach using Fuzzy set theory and Monte Carlo simulation has been developed to help evaluate the sustainability of alternative improvement options. The approach is required as previous methodologies only present desirability as a singular figure; and therefore decision makers are not provided with sufficient information on associated risk. The presented approach incorporates uncertainty throughout, and gives option desirability in terms of mean, standard deviation and variance. The risks using this method are better understood and can significantly aid industrial decision makers. The sustainability indicators and hybrid approach have been demonstrated using a case study in the manufacturing industry; to identify the most sustainable way to increase cure conversion within an oven. Amongst the three options: increasing oven size, increasing oven temperature and new product formulation, increasing oven temperature shows the highest desirability, while new product formulation though has a lower desirability has the highest certainty. Furthermore, a cumulative desirability distribution plot gives a basis to select option that is aligned with the business's risk strategy.

Key words: sustainability indicators; fuzzy set theory; monte carlo simulation; industrial ovens; manufacturing

Word count: 6687

\section{Nomenclature}

\begin{tabular}{rll}
\hline \multicolumn{1}{l|}{ Symbol } & Description \\
\hline$A$ & sustainability indicator \\
$w$ & Alternation option \\
$x$ & Score of indicator \\
$n$ & Number of indicators \\
$m$ & Number of alternative option \\
$f 1, f 2, f 3$ & Triangular fuzzy number \\
$\tilde{x}_{m n}$ & Normalized score for each indicator \\
$w_{n}$ & Weighted fuzzy number
\end{tabular}


$\tilde{c}_{m n} \quad$ Normalized weighted score for each indicator

$\tilde{r}_{m n} \quad$ Randomly generate number

$D$ Desirability

\section{Introduction}

Sustainable development concepts and practices are becoming increasingly common throughout the manufacturing industry, however research focused on increasing the sustainability of industrial ovens is still in its infancy. Ovens consume a sizeable portion of industrial energy (EERE, 2013), and significantly affect the performance capability and environmental impact of a manufacturing process. The three dimensions of sustainability can be applied to have specific relevance for industrial ovens. For example; environmental concern can result in pollution and waste. The ability to manufacture quality product affects economic performance, and employee's safety falls within the social dimension of sustainability. This research aims to enable cleaner and more responsible production in the manufacturing environment.

Sustainability indicators can be used to inform decisions and provide insight into complex issues by balancing the three sustainability dimensions (Kwatra et al., 2016). They can be used to compare differences between potential oven improvements, and therefore help to develop a sustainable industry. Application of indicators for technology assessment can be used in two ways; a) to assess the overall performance of a particular technology system, or b) to compare at least two technology systems. Indicators should be applied using 'fit for purpose' approach rather than making a generic set of indicators fit for all applications (Dewulf and Van Langenhove, 2005). Indicators can be quantitative or qualitative, and can fall within the categories of descriptive, performance or efficiency indicators (Hallstedt, 2015). A UN report (Nations, 2007) sets a number of guidelines when selecting appropriate indicators. In summary, they should be simple and informative and approaches should be uncomplicated and without a large number of sub sets. Indicators should be responsive to changes in the environment and related human activities. They should be clear, unambiguous and provide basis for comparison.

Environmental indicators may include greenhouse gas emission, energy consumption, renewability of resources, toxicity of emissions, re-use of materials, recoverability of waste materials and efficiency (Dewulf and Van Langenhove, 2005). Proposed economic indicators relevant to industrial ovens involve net sales, operational production costs, gross margin and overhead costs (Pannell and Glenn, 2000). And finally, social indicators tend to be toxicology or safety related (Al-Sharrah et al., 2007, Al-Sharrah et al., 2010).

As well as identifying a suitable set of sustainability indicators, it is also important to analyze the indicator set with a method of multi-criteria analysis appropriate for that particular application. For instance, Tokos et al. (2012) were able to develop a methodology for integrated sustainability performance assessment specifically for processing industries. Multi-criteria analysis is used to aid decision making by gathering information on a variety of criteria, or indicators, to understand how multiple objectives can best be achieved. It enables for indicators with different units to be assessed alongside each other. Fuzzy set theory is a long established field within multi-criteria analysis which presents a way to deal with problems which had previously been unsolvable by traditional multi-criteria analysis. It deals with approximation rather than exact reasoning (Zadeh, 1965), allowing for uncertainty to be assessed rationally by associating a grade of desirability to quantitative and qualitative data (Begić and Afgan, 2007, Niekamp et al., 2015, Fu, 2008). Fuzzy optimization is seen to be more robust than crisp optimization with Pareto optimum analysis as no iterative steps are required (Tay et al., 2011).

Fuzzy indicator sets including both qualitative and quantitative indicators have more recently been demonstrated as a method to assess sustainability indicators (Mendoza and Prabhu, 2004, Ducey and Larson, 1999), by enabling objective decision making of indicators, which may themselves be subjective. Uncertainty can result from imprecise measurements, average or outdated data using proxies and incomplete data, approximations in modelling, normalisation and weighting (Sadhukhan et al., 2014) assessment and linguistic descriptors by experts and their assigned values, in case of qualitative indicators. Uncertainty in the assessment of sustainable development causes issues when trying to solve problems using conventional multi-criteria analysis. Probabilistic theory is based on classical set theory which is defined by yes or no statements, and requires hard thresholds. Whereas Fuzzy theory is based on multi-valued logic and relates to events which have 
no well-defined meaning, allowing for the fuzziness to describe a degree to which an event occurs (and soft thresholds) (Cornelissen et al., 2001). Fuzzy sets do not have to be in or out, but are rather given a degree of membership. Fuzzy methods are useful when assessing complex or ill-defined problems, and can therefore be very useful for sustainability indicators. Fuzzy indicator uncertainty is not due to error or randomness, but attributed to generality, ambiguity or vagueness.

Monte Carlo simulation is a sampling technique used for result generation that depends on parameters given from probability distributions. Studies have been conducted that utilize both Monte Carlo simulation and Fuzzy set theory to evaluate sustainability indicator sets (Sadeghi et al., 2010, Loyd, 2004). Monte Carlo simulation requires the generation of random values to input into the model, where the model variables have a known range (as determined from a distribution type) but uncertain values in a particular event. Model variables can be provided by the triangular distributions generated in Fuzzy set theory. This technique is commonly used as a way to incorporate uncertainty into quantified risk assessment. Additionally there are guidelines for uncertainty analysis using Monte Carlo simulation for estimation and mitigation of uncertainty during environmental impact assessment (IPCC, 2006).

Although there has been valuable research into improving different aspects of industrial ovens (Pask et al., 2014, Khatir et al., 2015, Miah et al., 2014, Pask et al., 2016), an indicator set to assess overall oven sustainability has not previously been developed. This research is to provide a specific set of sustainability indicators that can be used to inform investment decisions for oven improvement and therefore provide a useful tool for manufacturing and process industries. The indicators are designed so that two or more alternative options can be evaluated to prioritize investment to deliver a more sustainable oven. To achieve this, a method of multicriteria analysis using Fuzzy set theory and Mont Carlo simulation has been developed which aims to assist decision makers by incorporating uncertainty into a final desirability level; thus providing information so that investments can be aligned with risk strategies. The applied methodology is an adaptation of previous approaches, and has been tailored to present findings in a way which is particularly useful for decision makers in the manufacturing and process industries. The indicator set and methodology have been demonstrated using an industrial case study.

\section{Methodology}

A set of sustainability indicators for industrial ovens is to be identified in section 3. This section details a hybrid method of multiple criteria decision making using Fuzzy set theory and Monte Carlo simulation to analyze sustainability indicators. Figure 1 outlines all important stages of the methodology, while the rest of this section details each step fully.

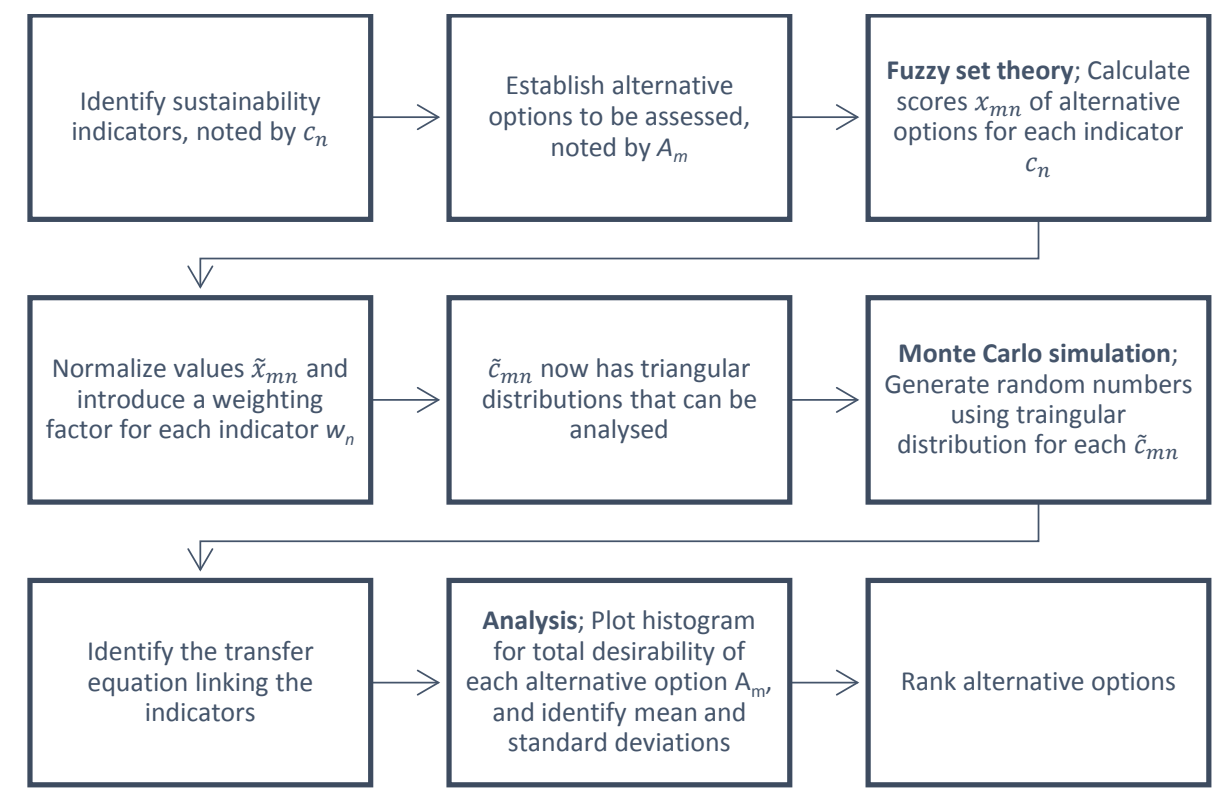

Figure 1: Flowchart of approach used for assessment of criteria using fuzzy optimization 
The methodology entails a multi-criteria decision analysis tool to identify a preferred option, $A_{m}$ amongst $m$ alternatives. The method evaluates alternative options through the use of indicators. Equation 1 displays the multi-criteria decision analysis matrix, where $c_{n}$ is the sustainability indicator, $x_{m n}$ is the indicator score, $m$ is the number of alternative option, and $n$ is the number of indicators. When using such an approach, the sustainability indicators and alternative options for system improvements should be defined by expert insights. The list should not be exhaustive; the indicators should be the most important ones without overlap between them and those that make a difference in the overall sustainability performances between options and thus help in the selection of the overall best option (Sadhukhan et al., 2014). The sustainability indicators of industrial ovens are presented in section 3.

$$
\begin{aligned}
& \begin{array}{lllll}
\text { Specific criteria } & C_{1} & C_{2} & \ldots & C_{n}
\end{array} \\
& \begin{array}{lllll}
\text { Weighting } & w_{1} & w_{2} & \ldots & w_{n}
\end{array} \\
& \text { Alternatives } \\
& x=\begin{array}{c}
A_{1} \\
A_{2} \\
\vdots \\
A_{m}
\end{array}\left(\begin{array}{cccc}
x_{11} & x_{11} & \ldots & x_{1 n} \\
x_{21} & x_{22} & \ldots & x_{2 n} \\
\vdots & \vdots & & \vdots \\
x_{m 1} & x_{m 2} & \ldots & x_{m n}
\end{array}\right)
\end{aligned}
$$

As previously stated, Fuzzy set theory is applied to multi-criteria decision problems to handle uncertainty of quantitative and qualitative criteria (Fu, 2008). It is likely that sustainability indicator sets will have both quantitative and qualitative information, and will inherently have a degree of uncertainty; thus highlighting why Fuzzy theory is appropriate for sustainability indicator analysis. The indicator score $x_{m n}$ is presented as a triangular fuzzy number $\left(f 1_{m n}, f 2_{m n}, f 3_{m n}\right)$. A triangular fuzzy number describes the membership grade function that a value for an indicator will occur; $f 1$ is the lower limit membership grade equal to $0, f 2$ is the most possible value membership grade equal to 1 (can be interpreted as the mean), and $f 3$ is the upper limit membership grade equal to 0 .

Fuzzy numbers for quantitative indicators can be identified in measureable unit. The task is to then convert quantitative scores $x_{m n}$ to normalized values between $0-1$, so that indicators can be directly compared to each other. Indicators are either a benefit or a cost having positive or negative effects on the system performance, respectively; benefit indicators should be maximized, while cost indicators should be minimized. Equation 2 shows the calculation to normalize scores for benefit indicators, and equation 3 for cost indicators. The normalized score $\tilde{x}_{m n}$ is calculated using $c_{n}^{+}$as the maximum score for $c_{n}$, and $c_{n}^{-}$the minimum score for $c_{n}$.

$\tilde{x}_{m n}=\left(\frac{f 1_{m n}}{c_{n}^{+}}, \frac{f 2 m n}{c_{n}^{+}}, \frac{f 3_{m n}}{c_{n}^{+}}\right)$

$\tilde{x}_{m n}=\left(\frac{c_{n}^{-}}{f 3_{m n}}, \frac{c_{n}^{-}}{f 2_{m n}}, \frac{c_{n}^{-}}{f 1_{m n}}\right)$

Qualitative assessment can be used for indicators where it is difficult to use numerical figures due to uncertainty or the nature of indicator. Fuzzy set theory is advantageous as it can analyze quantitative and qualitative data simultaneously. Table 1 displays the linguistic variables and associated fuzzy numbers used in this study. Linguistic variables are used in standard fuzzy partition to enable for an indicator score to be given a linguistic term, which then corresponds to a fuzzy set and numerical value. The numerical value for each linguistic variable was chosen to provide the necessary range of desirability on a scale of $0-1$, and also to provide sufficient resolution and distinction between the potential indicator scores that are seen in the case study example in Section 4.

Table 1: Linguistic values associated with fuzzy numbers for qualitative indicators

\begin{tabular}{ll}
\hline Linguistic variable & $\begin{array}{c}\boldsymbol{w}_{\boldsymbol{n}} \text { - weighted fuzzy number } \\
\left(\boldsymbol{f} \mathbf{1}_{\boldsymbol{m} \boldsymbol{n}}, \boldsymbol{f} \mathbf{2}_{\boldsymbol{m} \boldsymbol{n}}, \boldsymbol{f} \mathbf{3}_{\boldsymbol{m} \boldsymbol{n}}\right)\end{array}$ \\
\hline Very low (VL) & $(0.00,0.00,0.05)$ \\
Low (L) & $(0.05,0.15,0.3)$ \\
Medium (M) & $(0.15,0.3,0.45)$ \\
High (H) & $(0.35,0.5,0.65)$ \\
Very high (VH) & $(0.55,0.7,0.85)$ \\
Extremely high (EH) & $(0.7,0.85,1)$ \\
\hline
\end{tabular}


Weighted fuzzy numbers $\left(w_{n}\right)$ and the normalized scores $\left(\tilde{x}_{m n}\right)$ are used to determine $\tilde{c}_{m n}$ using Equation 4. The weighting factors are necessary as the indicators will not all have equal importance when creating a sustainable system. Weightings should be determined objectively through consultation with experts working in relevant fields. For each alternative option, $\tilde{c}_{m n}$ values provide a triangular distribution of desirability of each sustainability indicator.

$\tilde{c}_{m n}=w_{n} \cdot \tilde{x}_{m n}$

The Monte Carlo simulation is now used as a tool to evaluate $\tilde{c}_{m n}$ values simultaneously and to determine which alternative option is favourable while understanding uncertainty in the final results. $\tilde{c}_{m n}$ values are fuzzy numbers and therefore represent a triangular distribution that can be used as the model input variables for Monte Carlo simulation. Each alternative option now has $n$ number of distributions of desirability. The aim is to combine all these distributions into one meaningful level of desirability for each alternative option. Monte Carlo simulation is used to numerically solve the problem by aggregating information in a stochastic way.

Random numbers are generated using the distributions provided by $\tilde{c}_{m n}$; the lower, mode and upper inputs for the triangular distribution are provided by fuzzy numbers $\left(f 1_{m n}, f 2_{m n}, f 3_{m n}\right)$. The count of random numbers generated must be deemed sufficiently large; 10000 random numbers is reasonable (Esmalifalak et al., 2015).

The next task is to identify the transfer linking equation; used to combine all the indicators into one, enabling for overall desirability of each alternative options to be calculated. As the data is normalized and weighted, the indicators can be directly assessed against each other. Equation 5 displays the transfer linking equation, where $D\left(A_{m}\right)$ is the total desirability for alternative option $A_{m}$, and $\tilde{r}_{m n}$ is a randomly generate number for a given indicator. The desirability is provided between 0 and 1 .

$D\left(A_{m}\right)=\frac{\tilde{r}_{m 1}+\tilde{r}_{m 2}+\tilde{r}_{m 3} \ldots+\tilde{r}_{m n}}{n}$

Equation 5 is used to generate a data set of the total desirability for each alternative option. A normal distribution plot of the desirability can be created which determines the mean, variance and standard deviation; used to rank each alternative option. The higher the mean, the more desirable the option. The spread of data is used to indicate result certainty, which is a key advantage of using the proposed methodology. Furthermore, a cumulative distribution plot of each alternative option can be created to provide decision makers which outcome findings that can be aligned to a business's risk strategy. This is a development on previous methodologies as it provides decision makers with information of the desirability uncertainty.

Figure 2 demonstrates why knowledge of desirability uncertainty is beneficial. Each triangle represents the triangular distribution of desirability for alternative options $A_{1}, A_{2}$ and $A_{3}$ with the peak showing the mean, and the edges showing the variance. $A_{2}$ has a greater mean desirability than $A_{1}$, however there is more uncertainty in $A_{2}$ 's results. $A$ business may decide that it prefers $A_{1}$ despite the decreased mean, because they have more confident that the desirability will be within an acceptable range. Therefore Monte Carlo simulation presents the spread of data rather than just the mean, thus providing decision makers with all available information.

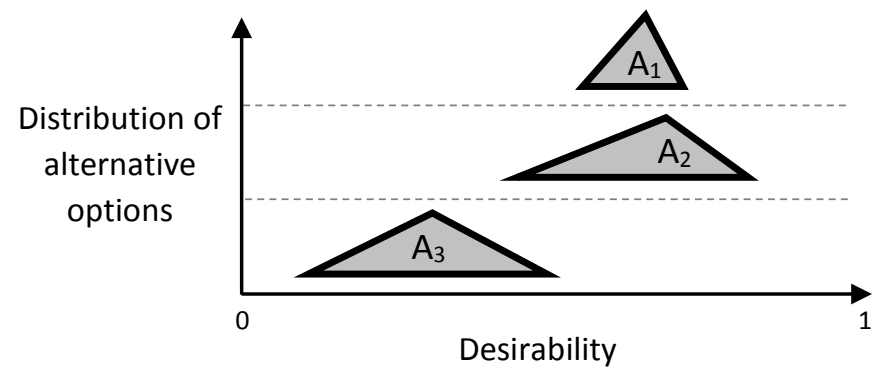

Figure 2: Graphical representation of desirability for alternative options $A_{1}, A_{2}, A_{3}$

A hybrid approach has been presented for the analysis of multiple criteria/indicators using Fuzzy set theory and Monte Carlo simulation. It requires basic statistical software and can be used across a wide range of industrial scenarios. The following section identifies specific sustainability indicators for industrial ovens, and then the intended use of methodology and indicator set is demonstrated in sections 4 . 


\section{Sustainability indicators for ovens}

A generic schematic diagram of an oven system is shown in Figure 3. Using this understanding, sustainability indicators for industrial ovens have been identified. Table 2 shows the overview of the seven sustainability indicators chosen for industrial ovens. The table highlights the primary sustainability theme for each indicator, indicator name, ID, suggested units, type of indicator, a short description and a rational behind the indicator selection. To keep the assessment framework simple, it has been intended that each indicator affects a primary sustainability theme (i.e. environmental, economic and social), although it is worth noting that in reality some indicators will impact more than one sustainability dimension. For instance, toxicity affects humans who interact with the oven process, and will also have environmental impacts e.g. as in the case of toxic airborne particulates which interact with local environmental receptors. The remainder of this section then goes into further detail describing all seven indicators.

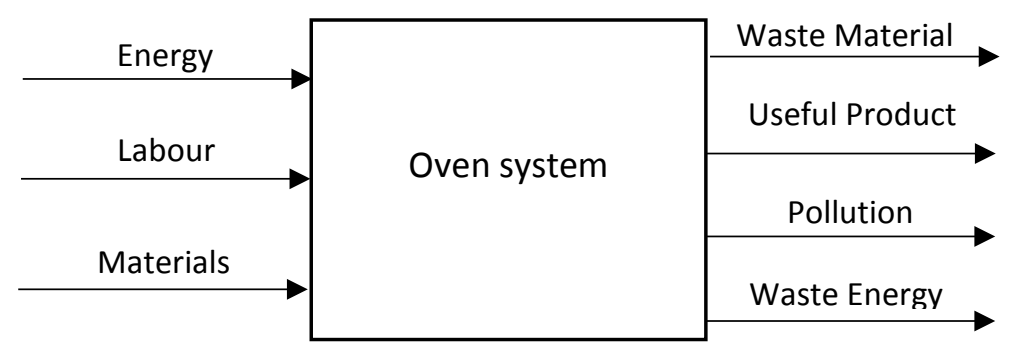

Figure 3: Generic schematic diagram of oven system

Table 2: Sustainability indicators

\begin{tabular}{|c|c|c|c|c|c|c|}
\hline Theme & Name & ID & Units & Type & Description & Rational \\
\hline \multirow[t]{2}{*}{ Env. } & $\begin{array}{l}\text { System air } \\
\text { flow }\end{array}$ & $\mathrm{C}_{1}$ & $\mathrm{~kg} / \mathrm{s}$ & Cost & $\begin{array}{l}\text { The mass flow rate } \\
\text { through the system }\end{array}$ & $\begin{array}{l}\text { Minimising system air flow } \\
\text { reduces over processing and } \\
\text { fuel consumption. }\end{array}$ \\
\hline & $\begin{array}{l}\text { Production } \\
\text { Efficiency }\end{array}$ & $\mathrm{C}_{2}$ & $\%$ & Benefit & $\begin{array}{l}\text { The efficiency of the } \\
\text { system to produce } \\
\text { product compared to } \\
\text { operation time }\end{array}$ & $\begin{array}{l}\text { High production efficiency } \\
\text { minimises waste generation } \\
\text { and energy consumption per } \\
\text { tonne of output. }\end{array}$ \\
\hline \multirow[t]{3}{*}{ Eco. } & $\begin{array}{l}\text { Operating } \\
\text { costs }\end{array}$ & $\mathrm{C}_{3}$ & $\mathrm{f} / \mathrm{hr}$ & Cost & $\begin{array}{l}\text { Cost of running the oven, } \\
\text { including labour, energy, } \\
\text { materials. }\end{array}$ & $\begin{array}{l}\text { Minimising operating costs is } \\
\text { beneficial for profit margins. }\end{array}$ \\
\hline & Quality & $\mathrm{C}_{4}$ & - & Benefit & $\begin{array}{l}\text { Quality improvement to } \\
\text { product (high, medium, } \\
\text { low, or no impact) }\end{array}$ & $\begin{array}{l}\text { High quality products ensure } \\
\text { high customer satisfaction. }\end{array}$ \\
\hline & $\begin{array}{l}\text { Capital } \\
\text { investment }\end{array}$ & $\mathrm{C}_{5}$ & $\begin{array}{l}f \\
\text { (000s) }\end{array}$ & Cost & $\begin{array}{l}\text { Capital investment } \\
\text { needed to get project off } \\
\text { the ground }\end{array}$ & $\begin{array}{l}\text { Lower capital expenditure } \\
\text { increases project viability } \\
\text { and is beneficial for a } \\
\text { business's cash flow. }\end{array}$ \\
\hline \multirow[t]{2}{*}{ Soc. } & Toxicity & $\mathrm{C}_{6}$ & $\mathrm{ppm}$ & Cost & $\begin{array}{l}\text { Residual monomer in } \\
\text { formulation and exhaust } \\
\text { used to assess the impact } \\
\text { on humans and } \\
\text { environment }\end{array}$ & $\begin{array}{l}\text { Low toxicity reduces } \\
\text { potential harm on operators } \\
\text { and environmental } \\
\text { receptors. }\end{array}$ \\
\hline & $\begin{array}{l}\text { Employment } \\
\text { Opportunity }\end{array}$ & $\mathrm{C}_{7}$ & - & Benefit & $\begin{array}{l}\text { The employment } \\
\text { opportunities generated } \\
\text { from an oven, job } \\
\text { numbers and skill level } \\
\text { required }\end{array}$ & $\begin{array}{l}\text { Increasing employment } \\
\text { opportunity results in an } \\
\text { engaged workforce and leads } \\
\text { to job satisfaction. }\end{array}$ \\
\hline
\end{tabular}


These seven indicators are directly related to industrial ovens, and the indicator scores are practically obtainable in real life industrial scenarios. A limited number of indicators increases the practicality and ease of use in an industrial setting. Greenhouse gas emissions as a potential indicator was not chosen because the system airflow and production efficiency indicators either control, or are determining factors for, GHG emissions and would capture any changes in GHG emissions. Similarly, other cost items such as gross margin and overhead costs are not separate indicators as the operating cost indicator captures the majority of this information.

\subsection{Detail for specific indicators}

\subsubsection{System air flow}

The target is to minimize the system air flow which passes through the oven system to a safe level while ensuring oven performance; resulting in reduced energy demand and environmental impact. This indicator is directly related to the greenhouse gas emissions and is a suitable measure for the industrial setting of this study. Low energy consumption is desirable to minimise an oven's impact on the environment as well as being cost effective for the business. There will be a lower limit for system air flow, and this can be determined by oven function or safety constraints (i.e. drying force, humidity, lower explosion limit). The physical set up of an oven can impact this indicator and optimization techniques can be used to minimize system air flow.

\subsubsection{Production efficiency}

Production efficiency is how efficient the system is in terms of production time compared to downtime. The downtime incorporates breakdowns, stoppages, heat up, cool down and can be affected by many aspects of the oven hardware, software, automation and interaction. A reliable and robust oven system can be constructed, and a well planned maintenance regime can ensure the oven equipment is working effectively. This ensures safety for workers, and has a large impact on the profitability of the process. Minimal unplanned downtime results in more manufacturing opportunity and positively impacts the production efficiency.

\subsubsection{Operating costs}

Operating costs are classified in two categories; fixed and variable operating costs. Fixed costs are independent of production rate/quantity and include maintenance, labor, taxation, insurance, overheads etc. Whereas variable rates are dependent on production and includes raw materials and utilities (Sahhukhan et al., 2014). This is an economic performance indicator and in many instances the operating costs are easily obtainable. The main aspects of oven modification which impact this indicator are the energy consumption, heating technology, materials for product formulation and human interaction.

\subsubsection{Quality}

Product quality is significantly affected by oven temperature uniformity and distribution. Product formulation can also impact the product quality. Quality is monitored within a manufacturing facility, however quality improvements can be overlooked when reviewing project options due to difficulty attributing quantitative improvement of a final product to a single unit oven process. In such cases, a linguistic description of quality improvement can be a suitable method of qualitative assessment. Table 1 displays the linguistic descriptions, and associated fuzzy numbers that can be used for this indicator. On top of the obvious waste issues resulting from poor quality, inconsistent products (that are still within quality tolerances) affect customer satisfaction and loyalty. This quality indicator captures both the economic and environmental dimensions of sustainability.

\subsubsection{Capital investment}

Although improvements should result in financial benefits to the business, there is often an initial capital investment required which has negative consequences to cash flow. The capital required for a modification should be estimated to a good degree of accuracy during an option approvals phase of a process. This indicator influences the economic performance of a business. It is clear that any business would want to have highest economic margin and minimize costs. Thus it is important to understand the direct costs of expenditure for a modification option. 


\subsubsection{Toxicity}

Toxic materials or exhaust emissions are common in many industrial heating processes and can be harmful to humans and the environment. At the very minimum toxicity must comply with regulations, but exceeding regulatory standards is beneficial. This indicator signifies the potential health impact by the evaluation of the extent of residual monomers in the product. The product formulation has the highest effect on toxicity of the industrial oven process. In the authors' industrial setting, the level of residual monomers is a suitable measure of this indicator. This indicator is primarily assessing the social aspect of industrial ovens.

\subsubsection{Employment opportunity}

The employment opportunity is an indicator of social performance and is viewed as a benefit. Employment opportunity can be increased by creating more jobs, or by increasing the skill level of existing jobs so that personnel have greater responsibility. Increasing the number of jobs can only be achieved if production demand increases, which can benefit a business, but also the individual. Increasing the skill level increases job satisfaction, responsibility and development. The head count required to operate an oven needs to be carefully calculated to ensure sufficient, but not excessive, manpower; this indicator ensures that workers are viewed as important stakeholders in such decisions. Linguistic descriptors are used to evaluate the potential change in employment opportunity, with the descriptions and associated fuzzy number found in Table 1.

\subsection{Weighting of indicator}

The importance of each indicator to sustainable decision making has been assessed by experts in the field of industrial oven management and sustainability. Fifteen individuals were asked to score each indicator between 0 and 1 for its importance when developing a sustainable oven ( 0 being least important, 1 being of most importance). This method of identifying indicator weightings is appropriate because it reflects the opinions of decision makers in industry and has sufficient input from experts across all three dimensions of sustainability. Fifteen opinions was deemed an appropriate number for the purpose of this study because of the balance of individual's knowledge backgrounds. Figure 4 displays the results with the box plot showing the median, lower and upper quartiles for each indicator. Triangular fuzzy number weightings, shown in Table 3, are given to each indicator which are then used in the multiple criteria analysis; the lower quartile becomes $f 1$, the median becomes $f 2$ and the upper quartile becomes $f 3$.

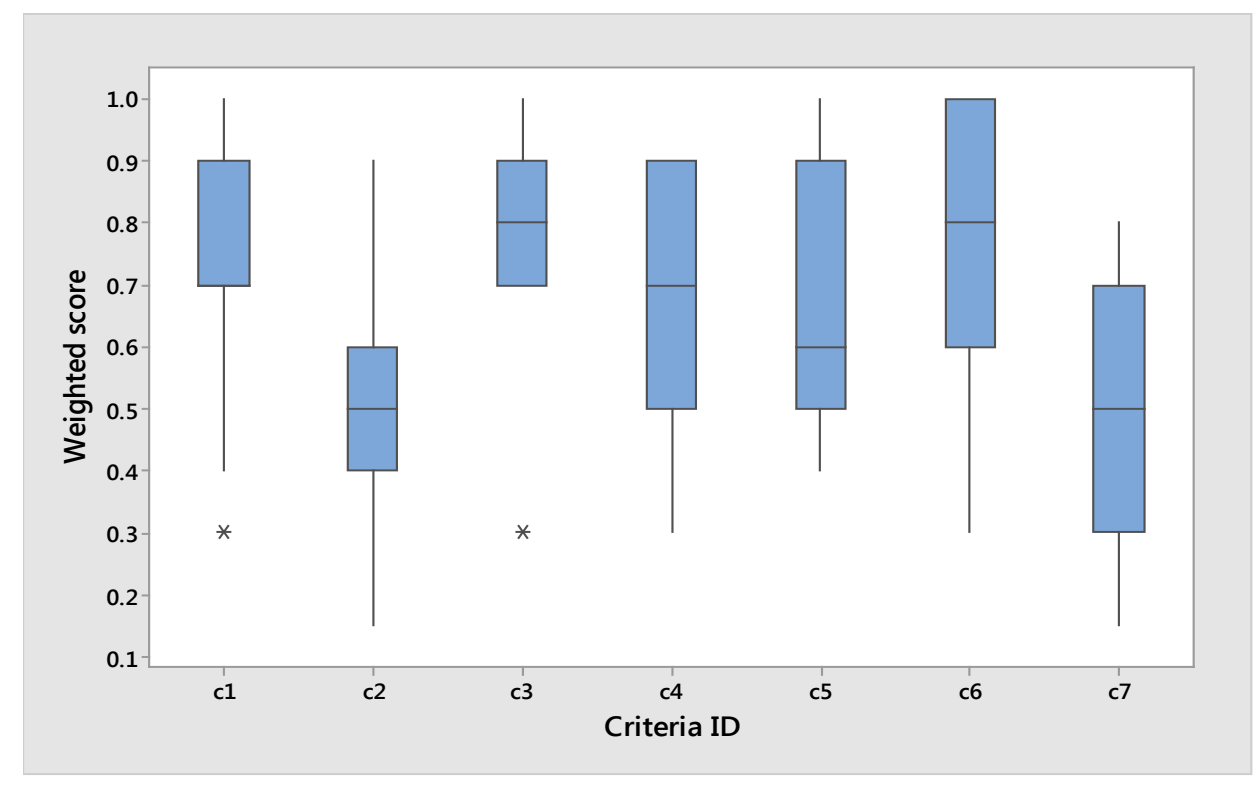

Figure 4: Box plot of weighted scores for sustainability indicators

Table 3: Weighting of indicators using fuzzy numbers

\begin{tabular}{|c|c|c|}
\hline Name of indicator & $\begin{array}{l}\text { Criteria } \\
\text { ID }\left(c_{n}\right)\end{array}$ & $\begin{array}{l}\text { Weighting using Fuzzy } \\
\text { numbers }\left(f 1_{n}, f 2_{n}, f 3_{n}\right)\end{array}$ \\
\hline System air flow & $\mathrm{C}_{1}$ & $(0.7,0.7,0.9)$ \\
\hline
\end{tabular}




\begin{tabular}{lll} 
Production Efficiency & $\mathrm{c}_{2}$ & $(0.4,0.5,0.6)$ \\
Operating costs & $\mathrm{c}_{3}$ & $(0.7,0.8,0.9)$ \\
Quality & $\mathrm{C}_{4}$ & $(0.5,0.7,0.9)$ \\
Capital investment & $\mathrm{C}_{5}$ & $(0.5,0.6,0.9)$ \\
Toxicity & $\mathrm{C}_{6}$ & $(0.6,0.8,1)$ \\
Employment opportunity & $\mathrm{c}_{7}$ & $(0.3,0.5,0.7)$ \\
\hline
\end{tabular}

\section{Case study}

To demonstrate applicability, the indicator set and methodology has been used to evaluate three different modification options to improve the sustainability of an industrial oven system. The oven's purpose is to treat an adhesive resin. It was identified that insufficient treatment was occurring in the current process, and therefore options were developed that would ensure sufficient treatment. The aim is to identify which of the three options outlined in Table 4 is the most sustainable.

Table 4: Alternative descriptions

\begin{tabular}{|c|c|}
\hline $\begin{array}{l}\text { Alternative } \\
\text { ID }\left(A_{m}\right)\end{array}$ & Description \\
\hline$A_{1}$ & $\begin{array}{l}\text { Increase size of the oven } \\
\text { Increase the size of the oven to increase time the product is exposed to a thermal regime. The } \\
\text { current process is constrained in terms of product throughput. }\end{array}$ \\
\hline$A_{2}$ & $\begin{array}{l}\text { Increase temperature within the oven } \\
\text { Increasing the temperature will result in more cure. This option will increase the temperature } \\
\text { within the oven by } x^{\circ} \mathrm{C} \text {. }\end{array}$ \\
\hline$A_{3}$ & $\begin{array}{l}\text { Change the product formulation } \\
\text { Use an additive in the product formulation in order to catalyze to the curing reaction. }\end{array}$ \\
\hline
\end{tabular}

Using the sustainability indicators for ovens provided in section 3, Table 5 displays the initial indicator scores for each alternative option. Furthermore, in Table 5 the values for $\mathrm{c}_{\mathrm{n}}^{+}$(maximum score for $\mathrm{c}_{\mathrm{n}}$ ) and $\mathrm{c}_{\mathrm{n}}^{-}$(minimum score for $\mathrm{c}_{\mathrm{n}}$ ) are given. These are used in equations 2 and 3 depending on whether the indicator is a cost or a benefit; therefore, the cost criteria have ' $n / a^{\prime}$ in the $c_{n}^{+}$column, and the benefit criteria have ' $n / a$ ' in the $c_{n}^{-}$ column.

Table 5: Individual indicator scores

\begin{tabular}{llllcc}
\hline Criteria ID & $\mathbf{A}_{\mathbf{1}}\left(\boldsymbol{x}_{\mathbf{1} \boldsymbol{n}}\right)$ & $\mathbf{A}_{\mathbf{2}}\left(\boldsymbol{x}_{\mathbf{2} \boldsymbol{n}}\right)$ & $\mathbf{A}_{\mathbf{3}}\left(\boldsymbol{x}_{\mathbf{3} \boldsymbol{n}}\right)$ & $\boldsymbol{c}_{\boldsymbol{n}}^{+}$ & $\boldsymbol{c}_{\boldsymbol{n}}^{-}$ \\
\hline $\mathrm{C}_{1}$ & $(20,21,22)$ & $(10,11,12)$ & $(10,11,12)$ & $\mathrm{n} / \mathrm{a}$ & 10 \\
$\mathrm{C}_{2}$ & $(40,50,60)$ & $(45,55,65)$ & $(50,55,65)$ & 65 & $\mathrm{n} / \mathrm{a}$ \\
$\mathrm{C}_{3}$ & $(1050,1100,1150)$ & $(800,850,900)$ & $(850,900,950)$ & $\mathrm{n} / \mathrm{a}$ & 800 \\
$\mathrm{C}_{4}$ & $(0.7,0.85,1)$ & $(0.35,0.5,0.65)$ & $(0.35,0.5,0.65)$ & 65 & $\mathrm{n} / \mathrm{a}$ \\
$\mathrm{C}_{5}$ & $(900,950,1000)$ & $(5,5,10)$ & $(10,15,20)$ & $\mathrm{n} / \mathrm{a}$ & 5 \\
$\mathrm{C}_{6}$ & $(0.7,0.8,0.9)$ & $(0.9,1.0,1.2)$ & $(0.9,1.1,1.2)$ & $\mathrm{n} / \mathrm{a}$ & 0.7 \\
$\mathrm{C}_{7}$ & $(0.15,0.3,0.45)$ & $(0.15,0.3,0.45)$ & $(0.15,0.3,0.45)$ & 0.45 & $\mathrm{n} / \mathrm{a}$ \\
\hline
\end{tabular}

Using the sustainability indicators for ovens provided in section 3, Table 6 shows the normalized quantitative and qualitative indicator scores $\left(\tilde{x}_{m n}\right)$ for each alternative option using equations 2 and 3 . These were determined using product and process understanding of the existing oven, as well as knowledge of how the alternative option would impact on each indicator. Linguistic values were used to generate fuzzy numbers for indicators $\mathrm{C}_{4}$ and $\mathrm{C}_{7}$.

Table 6: Quantitative and qualitative criteria for three alternative options

\begin{tabular}{lllll}
\hline Criteria ID & $\begin{array}{l}\text { Weight using fuzzy } \\
\text { numbers }\left(\boldsymbol{w}_{\boldsymbol{n}}\right)\end{array}$ & $\mathbf{A}_{\mathbf{1}}\left(\boldsymbol{x}_{\mathbf{1} \boldsymbol{n}}\right)$ & $\mathbf{A}_{\mathbf{2}}\left(\boldsymbol{x}_{\mathbf{2} \boldsymbol{n}}\right)$ & $\mathbf{A}_{\mathbf{3}}\left(\boldsymbol{x}_{\mathbf{3} \boldsymbol{n}}\right)$ \\
\hline $\mathrm{C}_{1}$ & $(0.7,0.7,0.9)$ & $(0.45,0.48,0.50)$ & $(0.83,0.91,1.00)$ & $(0.83,0.91,1.00)$ \\
$\mathrm{C}_{2}$ & $(0.4,0.5,0.6)$ & $(0.62,0.77,0.92)$ & $(0.69,0.85,1.00)$ & $(0.77,0.85,1.00)$ \\
$\mathrm{C}_{3}$ & $(0.7,0.8,0.9)$ & $(0.70,0.73,0.76)$ & $(0.89,0.94,1.00)$ & $(0.84,0.89,0.94)$
\end{tabular}




\begin{tabular}{lllll}
$C_{4}$ & $(0.5,0.7,0.9)$ & $(0.55,0.70,0.85)$ & $(0.15,0.30,0.45)$ & $(0.35,0.50,0.65)$ \\
$C_{5}$ & $(0.5,0.6,0.9)$ & $(0.01,0.01,0.01)$ & $(0.50,1.00,1.00)$ & $(0.25,0.33,0.50)$ \\
$C_{6}$ & $(0.6,0.8,1)$ & $(0.78,0.88,1.00)$ & $(0.58,0.70,0.78)$ & $(0.58,0.64,0.78)$ \\
$C_{7}$ & $(0.3,0.5,0.7)$ & $(0.05,0.15,0.30)$ & $(0.05,0.15,0.30)$ & $(0.05,0.15,0.30)$ \\
\hline
\end{tabular}

The weightings for each indicator, $w_{n}$, is multiplied by $\tilde{x}_{m n}$ using equation 4 for the $\tilde{c}_{m n}$ values, which are displayed in Table 7.

\begin{tabular}{llll}
\multicolumn{4}{l}{ Table 7: Normalised and weighted $\tilde{\boldsymbol{c}}_{\boldsymbol{m} \boldsymbol{n}}$ fuzzy matrix } \\
\hline $\begin{array}{l}\text { Indicator } \\
\text { ID }\end{array}$ & $\mathrm{A}_{\mathbf{1}}$ & & $\mathrm{A}_{\mathbf{3}}$ \\
\hline $\mathrm{C}_{1}$ & $(0.32,0.33,0.45)$ & $(0.58,0.64,0.90)$ & $(0.58,0.64,0.90)$ \\
$\mathrm{C}_{2}$ & $(0.25,0.38,0.55)$ & $(0.28,0.42,0.60)$ & $(0.31,0.42,0.60)$ \\
$C_{3}$ & $(0.49,0.58,0.69)$ & $(0.62,0.75,0.90)$ & $(0.59,0.71,0.85)$ \\
$C_{4}$ & $(0.28,0.49,0.77)$ & $(0.08,0.21,0.41)$ & $(0.18,0.35,0.59)$ \\
$C_{5}$ & $(0.00,0.00,0.01)$ & $(0.25,0.60,0.90)$ & $(0.01,0.02,0.05)$ \\
$C_{6}$ & $(0.47,0.70,1.00)$ & $(0.35,0.56,0.78)$ & $(0.35,0.51,0.78)$ \\
$C_{7}$ & $(0.02,0.08,0.21)$ & $(0.02,0.08,0.21)$ & $(0.02,0.08,0.21)$ \\
\hline
\end{tabular}

Using the triangular distribution given by the fuzzy numbers $\left(\tilde{c}_{m n}\right)$ for each indicator and option, 10000 random numbers were generated using statistical software. The overall desirability of each alternative option was calculated by combing the information from all seven indicators, using the transfer linking equation 5 . Figure 5 shows the histogram plot of desirability for each alternative option. It shows that the mean desirability of $A 1$ is 0.38 (left hand side plot), the desirability of A2 is 0.48 (right hand side plot), and the desirability of A3 is 0.42 (middle plot). Therefore, $A_{2}$ (to increase oven temperature) is the most sustainable option as it has the highest desirability. The advantage of presenting findings in this way is that the spread of data can be visualized; thus enabling more informed decision making. Figure 5 shows the largest spread of data for $A_{2}$, suggesting greatest uncertainty in the mean value of its desirability compared to the other two options. The narrowest spread of $A_{3}$ suggests that this carries the greatest certainty. But it has lower desirability than $A_{2}$.

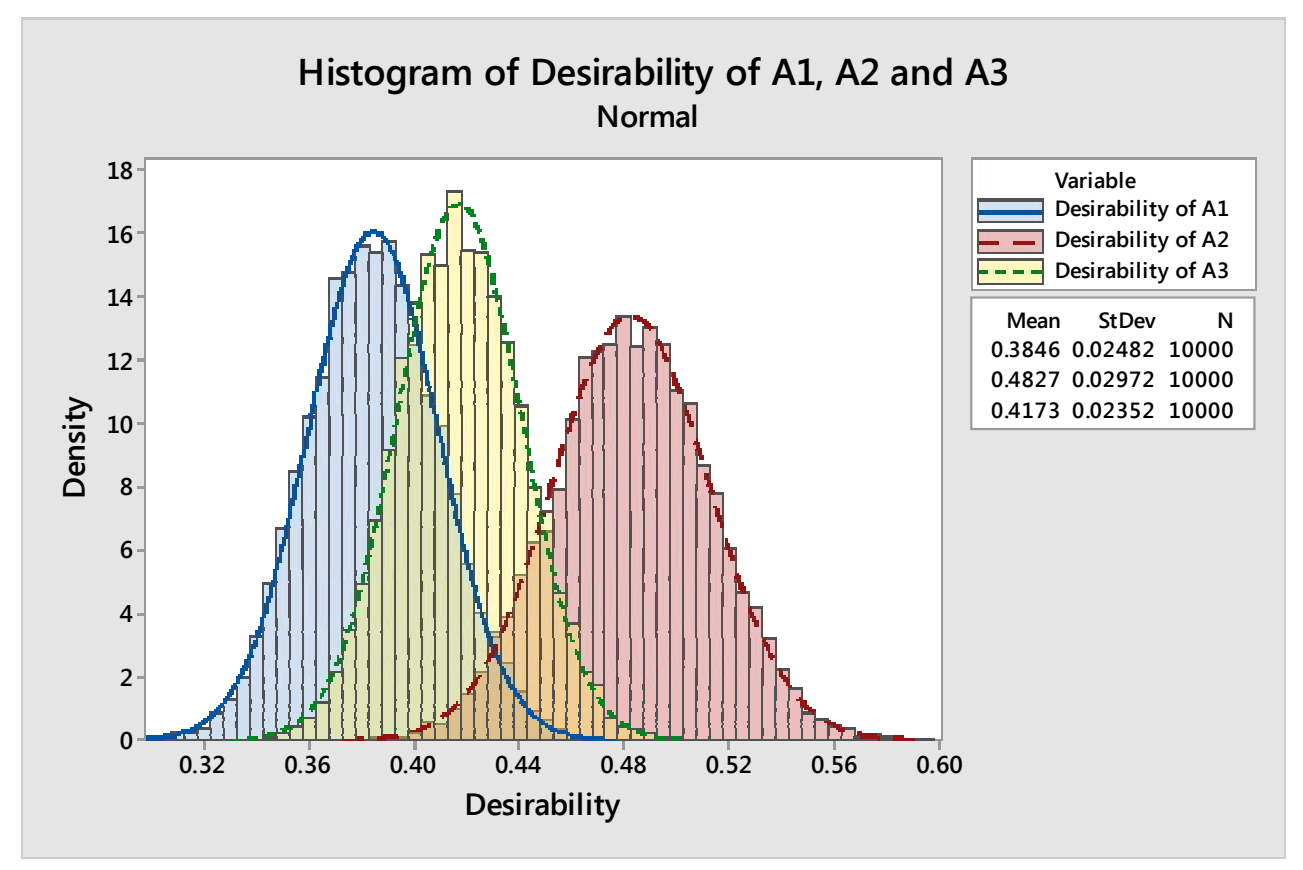

Figure 5: Histogram showing desirability of $A 1, A 2$, and $A 3$

A cumulative distribution plot can be generated with the data from the transfer linking equation 5 . Figure 6 shows the cumulative distribution of desirability for this case study. The advantage of presenting the data in the format is that the associated risks are more obvious. For instance, a business may decide that it requires a level 
of desirability of 0.43 . For option $A 1$, this will be achieved with a $1 \%$ certainty. For option $A 3$, this will be achieved with a $15 \%$ certainty. While for option A2, this will be achieved with a $95 \%$ certainty. Presenting findings using cumulative distributions can help align decisions to a company's risk acceptance levels.



Figure 6: Cumulative distribution of desirability

The analysis of sustainability indicators using Fuzzy set theory and Monte Carlo simulation has been communicated to decision makers within the manufacturing facility. The decision makers have therefore been provided with sufficient information to make an informed decision on how best to develop a sustainable oven system.

\section{Discussion}

There will inevitably be a degree of cross-over between indicators, however it is important to minimize replication in order to not skew findings. In the indicators presented, the operating cost includes fixed and variable costs. Fixed costs are those which do not change with sales or production, and it is important to try to separate these fixed costs from capital investment. Variable costs include the utility costs and will therefore be impacted on by the system air flow, which although is primarily an environmental measure, does impact on energy consumption. These have been taken into consideration and it was decided that the seven indicators are separate enough not to affect overall finding.

Indicator weighting can change depending on the desired purpose of the process being studied. A commodity business might have greater concern with initial capital or operating costs. However, a highly profitable industry would perhaps be less interested in costs and more interested in quality and throughput. The indicators and weightings presented in this paper have been designed for one particular industrial application, and there could therefore be industrial scenarios when they are not suitable. It is recommended that before any potential use, an evaluation of the industrial process and its supporting business should be conducted to fully understand the suitability of the presented indicator set.

Decision making when assessing sustainability from the perspectives of different disciplines is a difficult task. It is rare that one option can be definitively determined as more sustainable than another. There is often a significant degree of uncertainty, as well as cross over, with the sustainability performance of alternative options; therefore the method of multi-criteria analysis should reflect this. Being able to incorporate uncertainty using Fuzzy set theory has enhanced the practical application of sustainability indicators, however many previous approaches have fallen short on presenting uncertainty in the final results. The methodology used in 
this paper aids the decision making process further by providing all the information so that decisions can be aligned to business strategy.

Overall desirability of an option gives an indication of the sustainability. As the model in equations 1-5 incorporates scores of individual sustainability indicators given by experts as independent variables, these could be varied to examine their impacts on the sensitivity of the overall desirability of each option. If a particular indicator is found to impact desirability to an extent a different option becomes favourable, then the decision makers should investigate its uncertainty due causes (increasing the depth of the analysis) and involve more experts in the field (expanding the breadth of the analysis).

\section{Conclusion}

Sustainability indicators for technology assessment are essential to help decision makers identify suitable options. Having said this, the development of rigorous sustainability assessment for industrial ovens is in its infancy. In this study, a specific set of seven sustainability indicators has been developed for the assessment of an industrial oven; including system air flow, production efficiency, operating costs, quality, capital investment, toxicity and employment opportunity. Each indicator has been assigned a weighting through consultation with industrial oven and sustainability experts. The indicators have been chosen so that all aspects of sustainability are incorporated, and also with consideration of what information is readily available for industrial engineers. Such an indicator set for technology assessment of ovens has not previously been reported.

As well as identifying a specific set of sustainability indicators, this paper presents a hybrid method of multiple criteria decision analysis which can be used to evaluate the sustainability of alternative improvement options. The methodology incorporates Fuzzy set theory and Monte Carlo simulation. Both techniques are established tools to help decision makers in multiple criteria analysis by incorporating uncertainty into the analysis. They are commonly used with sustainability indicators due to the inherent uncertainty which is common with many indicators, however the approach presented in this paper is more effective due to the fact that it incorporates uncertainty into the final desirability. This provides industrial decision makers with greater information than many previous methodologies.

The sustainability indicators and multiple criteria analysis has been demonstrated in an industrial environment by evaluating three alternative options for oven improvement at a manufacturing facility. It was identified that the level of adhesive cure being achieved in the oven was not sufficient. Consequently, three alternative options to increase cure conversion were developed. The predicted performance of each alternative option was scored against the seven sustainability indicators, before analysis was performed to determine its desirability. Using a histogram of normal distribution of desirability and a cumulative distribution plot, the most sustainable option to provide improved treatment of an adhesive resin was identified, which is increasing the oven temperature. The hope is that this research can help to increase sustainability of industrial ovens throughout the manufacturing and process industries.

\section{Acknowledgments}

This work has been completed during an Engineering Doctorate research programme in collaboration with the University of Surrey and $3 \mathrm{M}$, and was funded by the Engineering and Physical Sciences Research Council (501100000266).

\section{References}

Al-Sharrah, G., Elkamel, A. \& Almanssoor, A. 2010. Sustainability indicators for decision-making and optimisation in the process industry: The case of the petrochemical industry. Chemical Engineering Science, 65, 1452-1461.

Al-Sharrah, G. K., Edwards, D. \& Hankinson, G. 2007. A New Safety Risk Index for Use in Petrochemical Planning. Process Safety and Environmental Protection, 85, 533-540.

Begić, F. \& Afgan, N. H. 2007. Sustainability assessment tool for the decision making in selection of energy system-Bosnian case. Energy, 32, 1979-1985. 
Cornelissen, A. M. G., Van Den Berg, J., Koops, W. J., Grossman, M. \& Udo, H. M. J. 2001. Assessment of the contribution of sustainability indicators to sustainable development: a novel approach using fuzzy set theory. Agriculture, Ecosystems \& Environment, 86, 173-185.

Dewulf, J. \& Van Langenhove, H. 2005. Integrating industrial ecology principles into a set of environmental sustainability indicators for technology assessment. Resources, Conservation and Recycling, 43, 419-432.

Ducey, M. J. \& Larson, B. C. 1999. A fuzzy set approach to the problem of sustainability. Forest Ecology and Management, 115, 29-40.

EERE. 2013. Process Heating [Online]. Washington, DC. Available: http://www1.eere.energy.gov/manufacturing/tech assistance/pdfs/em proheat bigpict.pd f [Accessed 27/11/2013.

Esmalifalak, H., Albin, M. S. \& Behzadpoor, M. 2015. A comparative study on the activity based costing systems: Traditional, fuzzy and Monte Carlo approaches. Health Policy and Technology, 4, 5867.

Fu, G. 2008. A fuzzy optimization method for multicriteria decision making: An application to reservoir flood control operation. Expert Systems with Applications, 34, 145-149.

Hallstedt, S. I. 2015. Sustainability criteria and sustainability compliance index for decision support in product development. Journal of Cleaner Production.

IPCC 2006. Intergovernmental Panel on Climate Change (IPPC) Guidelines for National Greenhouse Gas Inventories. Geneva, Switzerland.

Khatir, Z., Taherkhani, A. R., Paton, J., Thompson, H., Kapur, N. \& Toropov, V. 2015. Energy thermal management in commercial bread-baking using a multi-objective optimisation framework Applied Thermal Engineerig.

Kwatra, S., Kumar, A., Sharma, P., Sharma, S. \& Singhal, S. 2016. Benchmarking sustainability using indicators: An Indian case study. Ecological Indicators, 61, Part 2, 928-940.

Loyd, A. 2004. A comparison of fuzzy indices with monte carlo simulations for risk assessment at the preliminary stages of transit project planning. Master of Science in Environmental Protection Technical University of Szczecin

Mendoza, G. A. \& Prabhu, R. 2004. Fuzzy methods for assessing criteria and indicators of sustainable forest management. Ecological Indicators, 3, 227-236.

Miah, J. H., Griffiths, A., Mcneill, R., Poonaji, I., Martin, R., Yang, A. \& Morse, S. 2014. Heat integration in processes with diverse production lines: A comprehensive framework and an application in food industry. Applied Energy, 132, 452-464.

United Nations. 2007. Indicators of Sustainable Development: Guidelines and Methodologies. In: AFFAIRS, E. A. S. (ed.). New York.

Niekamp, S., Bharadwaj, U. R., Sadhukhan, J. \& Chryssanthopoulos, M. K. 2015. A multi-criteria decision support framework for sustainable asset management and challenges in its application. Journal of Industrial and Production Engineering, 32, 23-36.

Pannell, D. J. \& Glenn, N. A. 2000. A framework for the economic evaluation and selection of sustainability indicators in agriculture. Ecological Economics, 33, 135-149.

Pask, F., Lake, P., Yang, A., Tokos, H. \& Sadhukhan, J. 2016. Industrial oven improvement for energy reduction and enhanced process performance. Clean Technologies and Environmental Policy, 1-10.

Pask, F., Sadhukhan, J., Lake, P., Mckenna, S., Perez, E. \& Yang, A. 2014. Practical approach for engineers to optimise industrial ovens for energy saving. 17th Conference on Process Integration, Modelling and Optimisation for Energy Saving and Pollution Reduction. Prague, Czech Republic: Chemical Engineering Transaction.

Sadeghi, N., Fayek, A. R. \& Pedrycz, W. 2010. Fuzzy Monte Carlo Simulation and Risk Assessment in Construction. Computer-Aided Civil and Infrastructure Engineering, 25, 238-252.

Sadhukhan, J., Ng, K. S. \& Martinez-Hernandez, E. 2014. Biorefineries And Chemical Processes: Design, Integration and Sustainability Analysis, John Wiley \& Sons Ltd. 
Sahhukhan, J., Ng, K. S. \& Hernandez, E. M. 2014. Biorefineries and Chemical Processes; Design, Integration and Sustainability analysis, Wiley.

Tay, D. H. S., Ng, D. K. S., Sammons, N. E. \& Eden, M. R. 2011. Fuzzy Optimization Approach for the Synthesis of a Sustainable Integrated Biorefinery. Industrial \& Engineering Chemistry Research, 50, 1652-1665.

Tokos, H., Pintaric, Z. N. \& Kranjnc, D. 2012. An integrated sustainability performance assessment and benchmarking of breweries. Clean Technology and Environmental Policy, 14, 173-193.

Zadeh, L. A. 1965. Fuzzy sets. Information and Control, 8, 338-353. 